\title{
Chemical Components, Antitermite and Antifungal Activities of Cinnamomum parthenoxylon Wood Vinegar ${ }^{1}$
}

\author{
Morina ADFA $\mathbb{D}^{2, \dagger} \cdot$ Ari ROMAYASA ${ }^{2} \cdot$ Arif Juliari KUSNANDA ${ }^{2,3} \cdot$

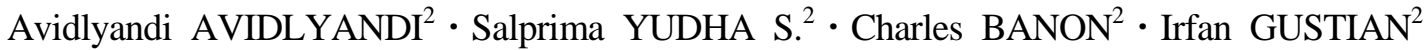

\begin{abstract}
Termiticidal and fungicidal activities of wood vinegar from Cinnamomum parthenoxylon (CP) stem wood have been evaluated against Coptotermes curvignathus and wood rotting fungi (Schizophyllum commune and Fomitopsis palustris). The utilized CP wood vinegar was produced in the operating temperature range $250-300^{\circ} \mathrm{C}$ pyrolysis. A no-choice test was applied for evaluating termiticidal activity with 33 active termites and antifungal activity using the agar media assay. The result showed that an increase in the concentrations of CP wood vinegar significantly raised the mortality of termite. CP wood vinegar showed high termiticidal activity, organic acids (acetic acid 42.91\%, 3-butenoic acid 6.89\%, butanoic acid, 2-propenyl ester 2.26\%), and ketones (1-hydroxy-2-propanone 5.14\%, 3-methylcyclopentane-1,2-dione 2.34\%) might be largely contributed to termiticidal activity in addition to other minor components. Furthermore, CP wood vinegar exhibited significant inhibition of fungal growth. These data showed that $\mathrm{CP}$ wood vinegar was more toxic to white-rot fungi (S. commune) than brown-rot (F. palustris). The results suggested that phenolic compounds from lignin degradation were responsible for good antifungal activity.
\end{abstract}

Keywords: wood vinegar, Cinnamomum parthenoxylon, termiticidal activity, GC-MS, fungicidal

\section{INTRODUCTION}

Some species of termites and rotting fungus are potential wood-destroying organisms thereby, leading to the economic loss of building materials. According to Kuswanto et al. (2015), subterranean termites are the most important wood pest in the world, with Formosan subterranean termite (Coptotermes) causing extensive damages in Asian countries. While, the white and brown rotting fungus plays an important role in damaging all wood components such as lignin, cellulose, and hemicellulose (Blanchette, 1995; Yoon et al., 2018).

Currently, a restriction has been placed on the application of insecticide and fungicide in preventing termiticidal and fungicidal activities on woods due to their adverse effect on human health and the surrounding environment. However, new safer treatment procedures have been investigated for practical use (Hadi et al.,

${ }^{1}$ Date Received November 17, 2019, Date Accepted January 16, 2020

${ }^{2}$ Department of Chemistry, Faculty of Mathematics and Natural Sciences, University of Bengkulu, Jalan W.R. Supratman, Bengkulu 38371, Indonesia

${ }^{3}$ Post Graduated Student, Department of Chemistry, Faculty of Mathematics and Natural Sciences, Andalas University, 25163 Limau Manis, Padang, Indonesia

† Corresponding author: Morina ADFA (e-mail: morina@unib.ac.id; morinaadfa@yahoo.com, ORCID: 0000-0002-7944-399) 
Morina ADFA - Ari ROMAYASA - Arif Juliari KUSNANDA - Avidlyandi AVIDLYANDI • Salprima YUDHA S. • Charles BANON • Irfan GUSTIAN

2018) with the development of pest control agents such as pyrethroids from Chrysanthemum genus and azadirachtin from Azadirachta indica with mild modes of action and are generally no persistent. Thus, plantderived natural products are promising alternatives for pest control agents for now and near future (Casida et al., 1983; Sidi et al., 2012; Mun and Nicholas, 2017).

Wood vinegar, also called pyroligneous acid, liquid smoke, pyrolysis water, smoke water, lignocelluloses biomass bio-oil, wood distillate or mokusaku, is a product processed by high-temperature carbonization of wood/biomass with absent of oxygen and has been widely used as a wood preservative, fungicide, repellent, insecticide, and herbicide (Tiilikkala et al., 2010; Arsyad et al., 2019).

Previously, we reported termiticidal activity of Toona sinensis wood vinegar against Coptotermes curvignathus and its chemical components. $T$. sinensis wood vinegar showed strong termiticidal activity (Adfa, 2017a). T. sinensis wood vinegar contains 40 constituents that were characteristic by GC-MS data. The organic compounds of $T$. sinensis wood vinegar were classified into carboxylic acids, phenols, ketones, amides, aldehydes, furans, esters, alcohols, a sugar derivative, and ether. The contents of organic fraction of $T$. sinensis wood vinegar which largely acetic acid (57.43\%) might act for the termiticidal activity.

Wood vinegar was obtained by $475^{\circ} \mathrm{C}$ pyrolysis reactor of a mixture of pine, spruce and fir wood particles showed a strong inhibiting activity of Trametes versicolor, Aspergillus niger and A. fumigatus. The chemical components of the softwood mixture was found to have high concentrations of catechol and 4methyl catechol (Suresh et al., 2019). Coconut shells and coir are used as raw materials to produce wood vinegar in Thailand. The wood vinegars were obtained from the carbonization process with temperatures ranging between $300-400^{\circ} \mathrm{C}$. Wood vinegar from coconut shells and the mixture of coconut shells and coir exhibited high termiticidal activity against workers termite of Odontotermes sp. at a dilution of 1:50. Acetic acid, formaldehyde, and phenols content of wood vinegars assume are the major cause of mortality of pest (Wititsiri, 2011).

Cinnamomum parthenoxylon belong to the Lauraceae family, and its crude methanol extract of leaves showed good termiticidal and antifeedant activity against Coptotermes curvignathus (Adfa et al., 2017b). Coumarin, flavonoids, benzenoids compounds which have been identified and isolated from the crude methanol extract might be responsible for its activity (Pardede et al., 2017; Wei et al., 2017). In continuing our research on potential C. parthenoxylon as a biopesticide, we would like to investigate the essential oil, extract, fractions, isolated compounds, and wood vinegar of $C$. parthenoxylon against termite and wood decay fungus.

To the best of our knowledge, until now no reported the anti-termite and anti-wood decay fungi activities of wood vinegar produced from stem wood of Cinnamomum parthenoxylon. In this study therefore, we evaluated the termiticidal activity of $C$. parthenoxylon wood vinegar against $C$. curvignathus as well as its antifungal activity against wood-rotting fungi Schizophyllum commune and Fomitopsis palustris.

\section{MATERIALS and METHODS}

\subsection{Materials}

Stem wood of Cinnamomum parthenoxylon (CP) was collected around the main Campus University of Bengkulu. Sample was cut into chip and then air-dried in the Organic Chemistry Laboratory, Department of Chemistry, University of Bengkulu. The material comprising of $\mathrm{NaOH}$, Oxalic acid anhydrous, Phenolphthalein, and Whatman No. 3 filter paper were purchased from Sigma-Aldrich, while Methanol and Potato Dextrose Agar (PDA) were purchased from Merck. 


\subsection{Pyrolysis and chemical components analysis of Cinnamomum parthenoxylon stem wood}

Wood vinegar was produced from burning air dried stem wood of Cinnamomum parthenoxylon (300 g) in a pyrolysis reactor at $250-300^{\circ} \mathrm{C}$ temperatures. This process was repeated three times with the collected wood vinegar stored at room temperature for two months to separate tar (Zhai et al., 2015), and the wood vinegar was weighed to calculate the yield.

The analysis of chemical components of $C$. parthenoxylon (CP) wood vinegar was carried out using GC-MS (Agilent Technologies 7890A GC with 5975C MS). MS run with hydrogen as carrier gas. A column HP-5MS (Agilent 19091S-436) with $30 \mathrm{~m}$ length, id $0.25 \mathrm{~mm}$ and $0.25 \mu \mathrm{m}$ film thickness was used as column and the maximum column temperature is $450^{\circ} \mathrm{C}$. Front inlet mode: splitless with initial temperature $250^{\circ} \mathrm{C}$, pressure $7.1282 \mathrm{psi}$, split flow $50 \mathrm{~mL} / \mathrm{min}$, and total flow $54 \mathrm{~mL} / \mathrm{min}$. The mass spectrometer was operated in electron-ionization (EI) mode and the mass spectra were obtained by Acquisition mode scan of the mass range from 40 to 450 .

The wood vinegar chemical components were identified based on their retention time (RT), with the mass spectra compared to Wiley and NIST library data of the GC-MS system. The percentage of components was calculated by the GC peak area, refers to Adfa et al. (2017a).

\subsection{Physicochemical properties}

Organic acid contents of CP wood vinegar was determined by the acid-base titration with $0.001 \mathrm{~N}$ $\mathrm{NaOH}$ and expressed as acetic acid (\%). The $\mathrm{pH}$ value of $\mathrm{CP}$ wood vinegar was measured by using a $\mathrm{pH}$ meter (HANNA HI-98107), while the density was measured by the pycnometer, odor and color were observed as well (Adfa et al., 2017a).

\subsection{Termiticidal activity}

Workers and soldiers of Coptotermes curvignathus Holmgren were collected from trees were attacked by termites around University of Bengkulu, and the termite was identified at School of biological sciences and technology, Institute Technology Bandung, Indonesia. The colony was maintained at $28^{\circ} \mathrm{C} \pm 2$ and $80 \% \pm$ $5 \mathrm{RH}$ in a container, and they fed wet filter paper until used for the test. A no-choice test was employed for evaluating termiticidal activity of CP wood vinegar according to the previous method. The concentrations of CP wood vinegar were prepared to $0 \%$ (solvent only, control), $2 \%, 4 \%, 6 \%$ and $8 \%$ (sample mass (mg)/filter paper mass $(\mathrm{mg}) \times 100 \%$ ). The samples were dissolved in $500 \mu \mathrm{L}$ ethanol and then the resulting solution was applied to filter papers (Whatman No. 3, diameter 90 $\mathrm{mm}$ ), and the papers were dried overnight at room temperature, continued two hours in a vacuum desiccator. The four replications were performed for each concentration. Subsequently, each dried filter paper was put in Petri dishes (90 mm in dia $\times 20 \mathrm{~mm}$ height), then thirty workers and three soldiers termites from the adult of active Coptotermes curvignathus were added. The Petri dishes were then placed on a wet cloth in a plastic tray and kept in a dark room at room temperature $\left(28^{\circ} \mathrm{C} \pm 2\right)$ and $80 \% \pm 5 \mathrm{RH}$ for 8 days. The number of termites dead was counted daily, with the termiticidal activity was evaluated from their average mortality rate (\%). For statistical analysis, Duncan's multiple comparison test were used to evaluate differences in percent mortality of termites. The results with $P<0.05$ were considered significant, with the calculations performed using statistical software SPSS 16.0 (Adfa et al., 2012; Adfa et al., 2013, 2017c).

\subsection{Antifungal activity}

The antifungal assay was conducted according to Kartal et al. (2004) and Oramahi et al. (2018) with 
Morina ADFA • Ari ROMAYASA • Arif Juliari KUSNANDA - Avidlyandi AVIDLYANDI • Salprima YUDHA S. • Charles BANON • Irfan GUSTIAN

modification. Cultures of a brown-rot fungi Fomitopsis palustris and a white-rot fungi Schizophyllum commune 7 days old grown on potato dextrose agar (PDA) plates at $25^{\circ} \mathrm{C}$ were used as inoculating. $\mathrm{CP}$ wood vinegar $0,0.2,0.5,0.7,0.9$, and $1 \% \mathrm{v} / \mathrm{v}$ in PDA media sterile was poured $15 \mathrm{~mL}$ into Petri dishes $(90 \mathrm{~mm}$ dia. $\times$ $20 \mathrm{~mm}$ high) and left to cool in room temperature, while the PDA only ( $0 \%$ wood vinegar) was used as control. The Petri dishes were then centrally inoculated with a single plug of each fungus after cutting with a cork-borer at $5 \mathrm{~mm}$ diameter. Three replicates were conducted for each condition. The treated and control dishes were incubated in a dark incubator at $25^{\circ} \mathrm{C}$ until the growth of fungi in controls reached the edge of the dishes and the diameter of the mycelium growth was measured. The percentage of mycelium inhibition rate was calculated by following equation:

$$
I=[(C-T) / C] \times 100 \%
$$

Where $I=$ =inhibition percentage; $C=$ diameter of mycelium growth in control Petri dishes (mm); and $T=$ diameter of mycelium growth in treated Petri dishes that containing the wood vinegar (mm).

\section{RESULTS and DISCUSSION}

\subsection{Wood vinegar of Cinnamomum parthenoxylon and its properties}

The characteristics and properties of wood vinegar are primarily influenced by the type of carbonaceous feedstocks as well as pyrolysis time and temperature pyrolysis (Mathew and Zakaria, 2015; Fengel and Wegener, 2011). The wood vinegar of Cinnamomum parthenoxylon (CP) stem wood was yellowish-brown in color, smoky in odor and transparent with yield $24.88 \%$. The total organic acids contained were 9.59\%, with density of $1.042 \mathrm{gcm}^{-3}$, and $\mathrm{pH}$ value of 3.57 .
Wada (1997) reported the criteria for good quality of the wood vinegar is using $\mathrm{pH}$ around 3 , specific gravity of $1.010-1.050 \mathrm{~g} \cdot \mathrm{mL}^{-1}$, with color visually pale yellow, bright brown or reddish-brown, smoky odor, transparent visually with no suspended matter, and the dissolved tar content not more than 3\%. According to Wada (1997), CP wood vinegar appeared to be of good quality in terms of odor, color, gravity, and transparency, except for $\mathrm{pH}$ value 3.5 that meet the Japanese standards.

The components of the CP wood vinegar were identified by GC/MS. The GC chromatogram of CP wood vinegar showed 42 chemical components (Fig. 1), and 30 components belonging to the seven groups were identified base on Mass Spectra data (Table 1). It also indicated that CP wood vinegar consist of carboxylic acids (53.76\%, 9 components), phenols (11.62\%, 6 components), ketones (9.19\%, 5 components), furans derivatives (6.41\%, 4 components), amines (3.4\%, 2 components), a few hydrocarbon aromatics (1.39\%, 2 components), and alcohols (0.90\%, 1 component). The result showed that organic acids were the primary components of $\mathrm{CP}$ wood vinegar, while acetic acid was the largest

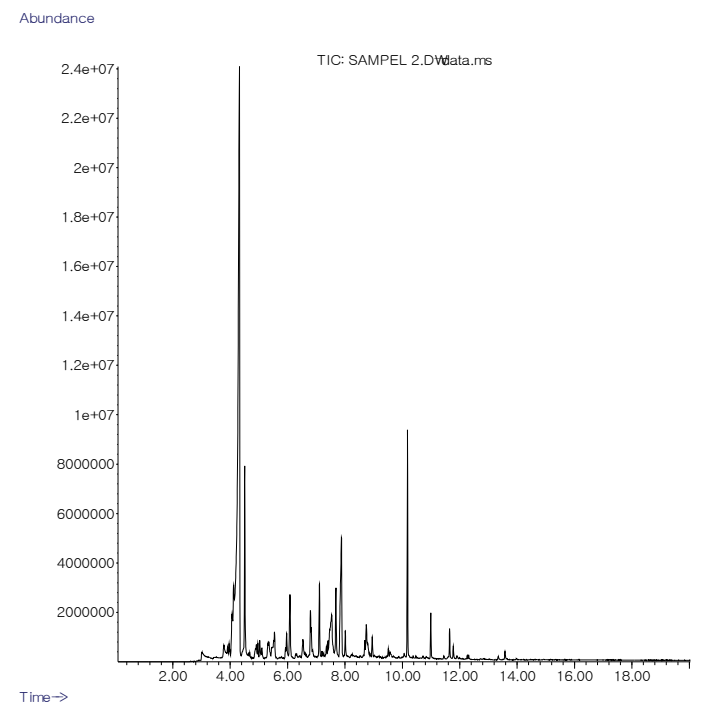

Fig. 1. GC chromatogram of Cinnamomum parthenoxylon wood vinegar. 
Table 1. Identified chemical components of Cinnamomum parthenoxylon wood vinegar

\begin{tabular}{|c|c|c|}
\hline $\begin{array}{l}\mathrm{RT} \\
(\mathrm{min})\end{array}$ & Compounds & $\begin{array}{l}\text { Peak area } \\
(\%)\end{array}$ \\
\hline 4.324 & Acetic acid & 42.91 \\
\hline 4.509 & 1-Hydroxy-2-propanone & 5.14 \\
\hline 4.917 & o-Isopropylhydroxylamine & 0.87 \\
\hline 4.970 & 2,2-Dimethyl-propanoic acid & 0.44 \\
\hline 5.107 & 2-Furanol, tetrahydro- & 0.44 \\
\hline 5.319 & Furan, 2,5-dimethyl- & 0.55 \\
\hline 5.351 & Furan, 2-methyl- & 0.91 \\
\hline 5.933 & 2-Cyclopenten-1-one, 2-methyl- & 0.28 \\
\hline 5.971 & Cyclopropyl carbinol & 0.98 \\
\hline 6.087 & Ethenamine, N-methyl-N-nitroso- & 2.54 \\
\hline 6.288 & Butanedioic acid, methylene- & 0.01 \\
\hline 6.542 & Phenol & 0.91 \\
\hline 6.606 & Pentanoic acid, 4-oxo-, methyl ester & 0.16 \\
\hline 6.802 & Butanoic acid, 2-propenyl ester & 2.26 \\
\hline 6.876 & Butanoic acid, 2-oxo- & 0.32 \\
\hline 7.114 & 3-Methylcyclopentane-1,2-dione & 2.34 \\
\hline 7.204 & Cyclopropane,1,2-dimethyl-3-methylene- & 0.21 \\
\hline 7.358 & Acetic acid, octyl ester & 0.43 \\
\hline 7.538 & 2-Furanmethanol, tetrahydro-, acetate & 4.51 \\
\hline 7.686 & 2-Methoxyphenol, & 2.46 \\
\hline 7.882 & 3-Butenoic acid & 6.89 \\
\hline 8.015 & Cyclohexanone, 4-ethyl- & 1.03 \\
\hline 8.692 & 2-Methoxy-4-methylphenol/Creosol & 0.45 \\
\hline 8.751 & 2-Hydroxyphenol/Catechol & 2.02 \\
\hline 9.513 & 4-Ethyl-2-methoxyphenol & 0.27 \\
\hline 10.180 & 2,6-Dimethoxyphenol & 5.51 \\
\hline 10.996 & 3,5-Dimethoxy-4-hydroxytoluene & 1.18 \\
\hline 11.652 & 5-ter-Butylpyrogallol & 0.90 \\
\hline 11.774 & $\begin{array}{l}\text { 2-Propanone, } \\
\text { 1-(4-hydroxy-3-methoxyphenyl)- }\end{array}$ & 0.40 \\
\hline 13.575 & 3,5-Dimethoxy-4-hydroxyphenylacetic acid & 0.34 \\
\hline
\end{tabular}

component (42.91\%) among 9 kinds of organic acids. Following organic acid phenols were the secondary compounds in CP wood vinegar, among them 2,6-dimethoxyphenol (5.51\%) was identified as the major phenol compound.

The chemical profiles of CP wood vinegar were an agreement with Zhai et al. (2015) that organic acids, phenolic compounds, ketones, aldehydes, benzene and its derivatives were the major components obtained at the temperature ranging $90-290^{\circ} \mathrm{C}$ pyrolysis range. Many studies have been conducted on the characterization of wood vinegar obtained from both slow and fast pyrolysis with the results dependent on the wood species and pyrolysis temperatures (Guillén, and Manzanos, 2005; Mun et al., 2007; Mohan et al., 2006, Adfa et al., 2017a). In addition, previous study was conducted on wood vinegar from Toona sinensis (TS) sawdust and produced in the pyrolysis reactor under conditions similar to this study. The results showed differences in physicochemical properties, with lower carboxylic acid and higher phenol components compared to TS wood vinegar. Lignocellulose materials such as wood are mainly composed of cellulose, hemicellulose, and lignin. The acetic acid to have originated from the acetyl groups in the hemicellulose (Kartal et al., 2004) and was the largest content of the wood vinegar obtained in the current study, whereas phenolic basically results from the thermal degradation of lignin (Mohan et al., 2008).

\subsection{Antitermite and antifungal activities of Cinnamomum parthenoxylon wood vinegar}

In this study, the daily termite mortality of $C$. curvignathus with $\mathrm{CP}$ wood vinegar was determined for 8 days by using the no-choice feeding test, with the results presented in Fig. 2 and their statistical analysis shown in Table 2. The mortalities were significantly increased with concentrations CP wood vinegar increased. At a concentration of $2 \%$, all termites were dead after 8 days, while at $4 \%$, and $6 \%$ the number of days reduced to 7 . The filter paper treated with $8 \%$ wood vinegar showed the fastest termite mortality among all concentrations and control, 100\% termite died on average after 6 days, and the significant difference at $P<0.05$ 
Morina ADFA · Ari ROMAYASA · Arif Juliari KUSNANDA • Avidlyandi AVIDLYANDI • Salprima YUDHA S. • Charles BANON • Irfan GUSTIAN

Table 2. Statistical analysis of termiticidal activity of Cinnamomum parthenoxylon wood vinegar

\begin{tabular}{|c|c|c|c|c|c|c|c|c|}
\hline \multirow{2}{*}{ Sample } & \multicolumn{8}{|c|}{ Mortality of termite $(\%)^{\mathrm{a}}$ over $1-8$ days } \\
\hline & 1 & 2 & 3 & 4 & 5 & 6 & 7 & 8 \\
\hline \multirow{2}{*}{$\begin{array}{l}\text { Control } \\
{[0 \%]}\end{array}$} & 0.00 & 0.00 & 0.00 & 0.00 & 0.00 & 0.00 & 0.00 & 0.00 \\
\hline & A & A & A & A & A & A & A & A \\
\hline \multirow{2}{*}{$\begin{array}{l}\text { Wood vinegar } \\
\text { [2\%] }\end{array}$} & 3.79 & 6.06 & 9.85 & 26.52 & 34.85 & 59.09 & 88.64 & 100 \\
\hline & $\mathrm{AB}$ & $\mathrm{AB}$ & $\mathrm{AB}$ & CD & $\mathrm{DE}$ & GHI & KLM & $\mathrm{M}$ \\
\hline \multirow{2}{*}{$\begin{array}{l}\text { Wood vinegar } \\
\text { [4\%] }\end{array}$} & 4.55 & 11.36 & 25.00 & 39.39 & 61.36 & 85.61 & 100 & 100 \\
\hline & $\mathrm{AB}$ & $\mathrm{AB}$ & CD & EF & HI & KL & $\mathrm{M}$ & $\mathrm{M}$ \\
\hline \multirow{2}{*}{$\begin{array}{l}\text { Wood vinegar } \\
\text { [6\%] }\end{array}$} & 5.30 & 12.12 & 27.27 & 54.55 & 77.27 & 93.94 & 100 & 100 \\
\hline & $\mathrm{AB}$ & $\mathrm{AB}$ & CD & GH & JK & LM & $\mathrm{M}$ & $\mathrm{M}$ \\
\hline \multirow{2}{*}{$\begin{array}{l}\text { Wood vinegar } \\
\text { [8\%] }\end{array}$} & 9.09 & 16.67 & 47.73 & 69.70 & 87.88 & 100 & 100 & 100 \\
\hline & $\mathrm{AB}$ & BC & FG & IJ & KLM & M & $\mathrm{M}$ & M \\
\hline
\end{tabular}

${ }^{a}$ Numbers followed by different letters (A-M) on mortality (\%) are significantly different at the level of $P<0.05$ according to Duncan multiple comparison test, $\mathrm{n}=5$ using 33 termites per replicate.

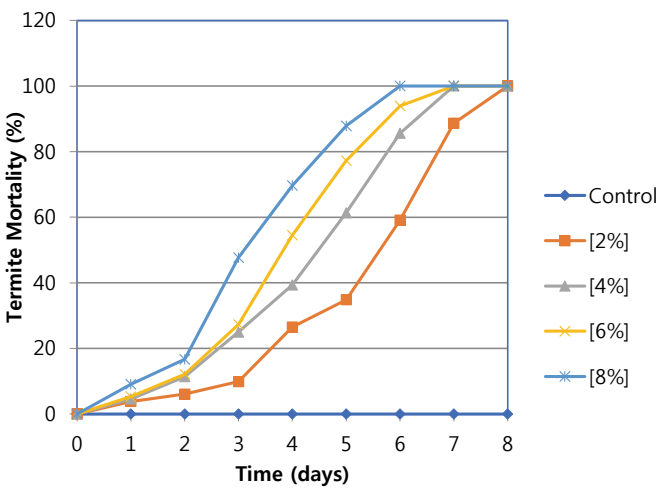

Fig. 2. Termiticidal activity of Cinnamomum parthenoxylon wood vinegar.

with Duncan's multiple comparison test to control and concentrations of 2 and $4 \%$ at 6 days. However, no significant difference with a concentration of $6 \%$ was observed on the 6 days. Organic acids (acetic acid 42.91\%, 3-butenoic acid 6.89\%, butanoic acid, 2-propenyl ester 2.26\%), and ketones (1-hydroxy-2-propanone 5.14\%, 3-methylcyclopentane-1,2-dione 2.34\%) might be largely contributed to termiticidal activity in addition to other minor components.

The termiticidal activity was performance consistent with the concentration of total acid in the wood vinegar, in good agreement with the previous report which used the wood vinegar made from Toona sinensis (TS) sawdust. TS wood vinegar showed strong termiticidal activity against Coptotermes curvignathus, evidenced at a concentration of $8 \%$ all termites dead after 3 days tested. It also contained $57.43 \%$ acetic acid which is responsible for the termiticide activity (Adfa et al., 2017a). According to Oramahi and Yoshimura (2013), the wood vinegar obtained from Vitex pubescens wood exhibited termiticidal activities against Reticulitermes speratus and Coptotermes formosanus, and its total acid concentration influenced anti termite activity. Yatagai et al. (2002) reported that acetic acid is the largest content of wood vinegar made from mixed chips of Cryptomeria japonica and Pseudotsuga menziesii; Quercus serrate and Pinus densiflora exhibited high termiticidal activity against $R$. speratus.

$\mathrm{CP}$ wood vinegar exhibited significant inhibition of the fungal growth. The mycelium growth of Schizophyllum commune and Fomitopsis palustris on the test medium and control is shown in Table 3, while the antifungal activity is summarized in Fig. 3. In addition, its inhibition growth against white-rot fungi (S. commune) at the various concentrations of $0,0.2$, $0.5,0.7,0.9$, and $1 \% \mathrm{v} / \mathrm{v}$ were $0,10.74,30.12,91.66$, 100 , and $100 \%$, respectively. While, the inhibition growth 
Table 3. The mycelium growth of Schizophyllum commune and Fomitopsis palustris on the test medium and control

\begin{tabular}{|c|c|c|c|c|c|c|}
\hline $\begin{array}{l}\text { Wood rotting } \\
\text { fungi }\end{array}$ & $\begin{array}{c}\text { Control } \\
{[0 \%]}\end{array}$ & $\begin{array}{c}\text { Wood vinegar } \\
{[0.2 \%]}\end{array}$ & $\begin{array}{c}\text { Wood vinegar } \\
{[0.5 \%]}\end{array}$ & $\begin{array}{c}\text { Wood vinegar } \\
{[0.7 \%]}\end{array}$ & $\begin{array}{c}\text { Wood vinegar } \\
{[0.9 \%]}\end{array}$ & $\begin{array}{c}\text { Wood vinegar } \\
{[1.0 \%]}\end{array}$ \\
\hline $\begin{array}{l}\text { Schizophyllum } \\
\text { commune }\end{array}$ & & & & 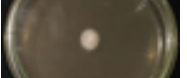 & . & - \\
\hline $\begin{array}{c}\text { Fomitopsis } \\
\text { palustris }\end{array}$ & 6 & & & & & \\
\hline
\end{tabular}

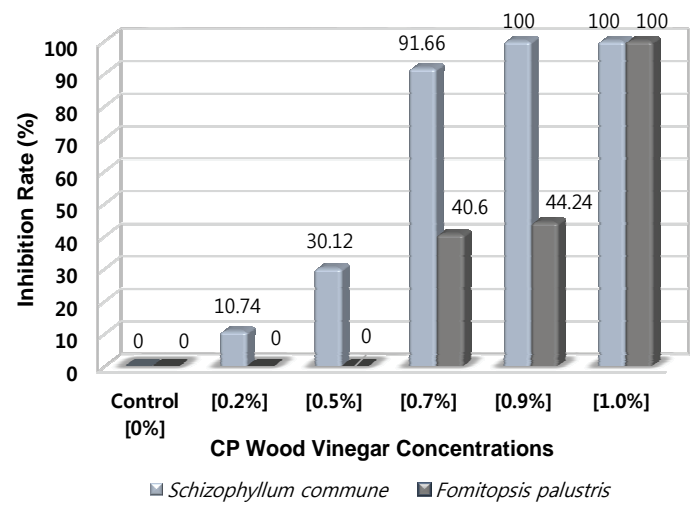

Fig. 3. Antifungal activity of Cinnamomum parthenoxylon wood vinegar against wood rotting fungi (Schizophyllum commune and Fomitopsis palustris).

against brown-rot fungi ( $F$. palustris) at the same concentrations tested were $0,0,0,40.6,44.24$, and $100 \%$ respectively.

The inhibition growth of $\mathrm{CP}$ wood vinegar against S. commune at low concentrations of $0 \%$ until $0.5 \%$ $\mathrm{v} / \mathrm{v}$ showed a steady increased from $0 \%$ to $30.12 \%$. The growth further increased sharply after the concentration changed to $0.7 \%$, three-fold gain compared with $0.5 \%$. Interestingly, there was $100 \%$ inhibition growth when the CP wood vinegar concentration changed to 0.9 and $1 \%$. In contrast, at a low concentration test from 0 to $0.5 \% \mathrm{v} / \mathrm{v}$, the $\mathrm{CP}$ wood vinegar failed to inhibit the mycelium growth of $F$. palustris, whereas moderate growth of $40.6 \%$ and $44.24 \%$ when the concentration changed to 0.7 and $0.9 \% \mathrm{v} / \mathrm{v}$. Interestingly, the inhibition growth of $F$. palustris increased sharply to $100 \%$ at a $1 \%$ concentration. These data showed that $\mathrm{CP}$ wood vinegar was more toxic to white-rot fungi than brown-rot fungi using the agar media assay.

Celimene et al. (1999) stated that stilbenes (pinosylvin, pinosylvin monomethyl ether, and pinosylvin dimethyl ether) were more toxic to white-rot fungi than brown-rot fungi using the agar media assay. According to Oramahi et al. (2018), the wood vinegar produced from the oil palm trunk at pyrolysis temperature $350^{\circ} \mathrm{C}$ greatly inhibited white-rot fungi growth (T. versicolor) at concentrations of 1.0 and 1.5\%. However, higher concentrations were required to inhibit $F$. palustris growth (brown rot fungi).

Another report by Theapparat et al. (2014) that antifungal activity of wood vinegar from Eucalyptus camaldulensis, Leucaena leucocephala, Azadirachta indica, Hevea brasiliensis (rubberwood) and Dendrocalamus asper (bamboo) against two white rot fungi (Trametes versicolor and Rigidoporopsis amylospora), a brown rot fungus (Gloeophyllum trabeum) and a sapstain fungus (Botryodiplodia theobromae) was investigated. 
Morina ADFA · Ari ROMAYASA - Arif Juliari KUSNANDA • Avidlyandi AVIDLYANDI • Salprima YUDHA S. • Charles BANON • Irfan GUSTIAN

All wood vinegar exhibited antifungal activities, among them wood vinegar made from bamboo and rubberwood showed greater activity which had higher total phenolic concentrations.

Many studies have also suggested that phenolic compound from lignin degradation were responsible for good antifungal activity (Kartal et al., 2004; Nakai et al., 2007; Mohan et al., 2008). There is ongoing research to investigate the efficacy of CP wood vinegar as a repellent agent against $C$. curvignathus and inhibiting of $T$. versicolor and Rhizopus oryzae growth.

\section{CONCLUSION}

In conclusion, the production of wood vinegar from C. parthenoxylon stem wood using a pyrolysis reactor at $250-300^{\circ} \mathrm{C}$ temperatures exhibited promising antitermite and anti-wood decay fungi activities. The growth of $S$. commune and F. palustris at 0.9 and $1 \%$ concentrations, were successively inhibited $100 \%$ by $\mathrm{CP}$ wood vinegar. At the lowest concentration tested (2\%) $100 \%$ termite dead after 8 days tested, when the concentration raised to $8 \%$ all termite dead on average after 6 days. The organic acid and phenols might be responsible for both activities. CP wood vinegar has the potential to prevent attacks by $C$. curvignathus, $S$. commune and F. palustris. The next study need to further investigate which components of wood vinegar are responsible for antitermite and anti-wood decay fungi activity singly.

\section{ACKNOWLEDGMENT}

The authors are grateful to the Ministry of Research, Technology and Directorate General of Higher Education the Republic of Indonesia (Fundamental Grant 165/SP2H/LT/DPRM/2019) for their financial support.

\section{REFERENCES}

Adfa, M., Hattori, Y., Yoshimura, T., Koketsu, M. 2012. Antitermite activity of 7-alkoxycoumarins and related analogs against Coptotermes formosanus Shiraki. International Biodeterioration \& Biodegradation 74: 29-135.

Adfa, M., Hattori, Y., Ninomiya, M., Funahashi, Y., Yoshimura, T., Koketsu, M. 2013. Chemical constituents of Indonesian plant Protium javanicum Burm. f. and their antifeedant activities against Coptotermes formosanus Shiraki. Natural Product Research 27(3): 270-273.

Adfa, M., Kusnanda, A.J., Saputra, W.D., Banon, C., Efdi, M., Koketsu, M. 2017a. Termiticidal activity of Toona sinensis wood vinegar against Coptotermes curvignathus Holmgren. Rasayan Journal of Chemistry 10(4): 1088-1093.

Adfa, M., Sanusi, A., Manaf, S., Gustian, I., Banon, C. 2017b. Antitermitic activity of Cinnamomum parthenoxylon leaves against Coptotermes curvignathus. Oriental Journal of Chemistry 33(6): 3063-3068.

Adfa, M., Kusnanda, A.J., Livandri, F., Rahmad, R., Darwis, W., Efdi, M., Ninomiya, M., Koketsu, M. 2017c. Insecticidal activity of Toona sinensis against Coptotermes curvignathus Holmgren. Rasayan Journal of Chemistry 10(1): 153-159.

Arsyad, W.O.M., Basri, E., Hendra, D., Trisatya, D.R. 2019. Termite resistance of impregnated Jabon wood (Anthocephalus cadamba Miq.) with combined impregnant agents. Journal of the Korean Wood Science and Technology 47(4): 451-458.

Blanchette, R.A. 1995. Degradation of the lignocellulose complex in wood. Canadian Journal of Botany 73(S1): S999-S1010.

Casida, J.E., Gammon, D.W., Glickman, A.H., Lawrence, L.J. 1983. Mechanisms of selective action of pyrethroid insecticides. Annual Review of 
Pharmacology and Toxicology 23(1): 413-438.

Celimene, C.C., Micales, J.A., Ferge, L., Young, R.A. 1999. Efficacy of pinosylvins against white-rot and brown-rot fungi. Holzforschung 53(5): 491-497.

Fengel, D., Wegener, G. eds. 2011. Wood: chemistry, ultrastructure, reactions. Walter de Gruyter, Berlin, Germany.

Guillén, M.D., Manzanos, M.J. 2005. Characteristics of smoke flavourings obtained from mixtures of oak (Quercus sp.) wood and aromatic plants (Thymus vulgaris L. and Salvia lavandulifolia Vahl.). Flavour and Fragrance Journal 20(6): 676-685.

Hadi, Y.S., Massijaya, M.Y., Zaini, L.H., Abdillah, I.B., Arsyad, W.O.M. 2018. Resistance of methyl methacrylate-impregnated wood to subterranean termite attack. Journal of the Korean Wood Science and Technology 46(6): 748-755.

Kartal, S.N., Imamura, Y., Tsuchiya, F., Ohsato, K. 2004. Preliminary evaluation of fungicidal and termiticidal activities of filtrates from biomass slurry fuel production. Bioresource Technology 95(1): 41-47.

Kuswanto, E., Ahmad, I., Dungani, R. 2015. Threat of subterranean termites attack in the Asian countries and their control: A review. Asian Journal of Applied Sciences 8(4): 227-239.

Mathew, S., Zakaria, Z.A. 2015. Pyroligneous acid-the smoky acidic liquid from plant biomass. Applied Microbiology and Biotechnology 99(2): 611-622.

Mohan, D., Pittman Jr, C.U., Steele, P.H. 2006. Pyrolysis of wood/biomass for bio-oil: a critical review. Energy \& Fuels 20(3): 848-889.

Mohan, D., Shi, J., Nicholas, D.D., Pittman Jr, C.U., Steele, P.H., Cooper, J.E. 2008. Fungicidal values of bio-oils and their lignin-rich fractions obtained from wood/bark fast pyrolysis. Chemosphere 71(3): 456-465.

Mun, S.-P., Ku, C.-S., Park, S.-B. 2007. Physicochemical characterization of pyrolyzates produced from carbonization of lignocellulosic biomass in a batch-type mechanical kiln. Journal of Industrial and Engineering Chemistry 13(1): 127-132.

Mun, S.-P., Nicholas, D.D., 2017. Effect of proanthocyanidin-rich extracts from Pinus radiata bark on termite feeding deterrence. Journal of the Korean Wood Science and Technology 45(6): 720-727.

Nakai, T., Kartal, S.N., Hata, T., Imamura, Y. 2007. Chemical characterization of pyrolysis liquids of wood-based composites and evaluation of their bio-efficiency. Building and Environment 42(3): 1236-1241.

Oramahi, H.A.,Yoshimura, T. 2013. Antifungal and antitermitic activities of wood vinegar from Vitex pubescens Vahl. Journal of Wood Science 59(4): 344-350.

Oramahi, H.A., Yoshimura, T., Diba, F., Setyawati, D., Nurhaida. 2018. Antifungal and antitermitic activities of wood vinegar from oil palm trunk. Journal of Wood Science 64(3): 311-317.

Pardede, A., Adfa, M., Kusnanda, A.J., Ninomiya, M., Koketsu, M. 2017. Flavonoid rutinosides from Cinnamomum parthenoxylon leaves and their hepatoprotective and antioxidant activity. Medicinal Chemistry Research 26(9): 2074-2079.

Sidi, M.B., Islam, M.T., Ibrahim, Y., Omar, D. 2012. Effect of insecticide residue and spray volume application of azadirachtin and rotenone on Trichogramma papilionis (Hymenoptera: Trichogrammatidae). International Journal of Agriculture and Biology 14(5): 805-810.

Suresh, G., Pakdel, H., Rouissi, T., Brar, S.K., Fliss, I., Roy, C. 2019. In vitro evaluation of antimicrobial efficacy of pyroligneous acid from softwood mixture. Biotechnology Research and Innovation 3: 47-53.

Theapparat, Y., Chandumpai, A., Leelasuphakul, W., Laemsak, N., Ponglimanont, C. 2014. Physicochemical 


\section{Morina ADFA - Ari ROMAYASA - Arif Juliari KUSNANDA • Avidlyandi AVIDLYANDI • Salprima YUDHA S. • Charles BANON • Irfan GUSTIAN}

characteristics of wood vinegars from carbonization of Leucaena leucocephala, Azadirachta indica, Eucalyptus camaldulensis, Hevea brasiliensis and Dendrocalamus asper. Kasetsart Journal-Natural Science 48(6): 916-938.

Tiilikkala, K., Fagernäs, L., Tiilikkala, J. 2010. History and use of wood pyrolysis liquids as biocide and plant protection product. The Open Agriculture Journal 4: 111-118.

Wada, T. 1997. Charcoal Handbook. Forest management section, agriculture, forestry and fisheries division, Bureau of labour and economic affairs, Tokyo Metropolitan Government. Tokyo, Japan, pp.92. Wei, X., Li, G.H., Wang, X.L., He, J.X., Wang, X.N., Ren, D.M., Lou, H.X., Shen, T. 2017. Chemical constituents from the leaves of Cinnamomum parthenoxylon (Jack) Meisn (Lauraceae). Biochemical Systematics and Ecology 70: 95-98.
Wititsiri, S. 2011. Production of wood vinegars from coconut shells and additional materials for control of termite workers, Odontotermes sp. and striped mealy bugs, Ferrisia virgata. Songklanakarin Journal of Science \& Technology 33(3): 349-354. Yatagai, M., Nishimoto, M., Hori, K., Ohira, T. Shibata, A. 2002. Termiticidal activity of wood vinegar, its components and their homologues. Journal of Wood Science 48(4): 338-342.

Yoon, S.-M., Kim, Y.-S., Kim, Y.-K., Kim, T.-J. 2018. A novel endo- $\beta$-1, 4-xylanase from Acanthophysium sp. KMF001, a wood rotting fungus. Journal of the Korean Wood Science and Technology 46(6): 670-680.

Zhai, M., Shi, G., Wang, Y., Mao, G., Wang, D., Wang, Z. 2015. Chemical compositions and biological activities of pyroligneous acids from walnut shell. BioResources 10(1): 1715-1729. 